\title{
Physical and chemical changes in the endive plants (Cichorium endivia L. var. crispum) during developmental stages
}

\begin{abstract}
The experiment was carried out on endive plant (Cichorium endivia L var.crispum) cv. Salad King during the two successive seasons of 2012/2013 and 2013/2014 to study the physical and chemical changes in plant during their developmental stages. The results of plant physical characteristics such as longest endive plant and highest leaves number per plant were obtained at the age of 90days. On the same curvilinear trend exhibit the highest yield per plant was obtained from endive plants at the age of 90days. Plant chlorophyll content, ascorbic acid, total sugars, dry weight and insulin increased continuously till the age of 90days followed with slight decrement happened till the age of 120 days. The content of nitrogen, phosphorus and potassium increased quickly up to the age of 90 days then it decreased slowly in the last following ages till the age of 120days illustrating a parabola curve trend.
\end{abstract}

Keywords: endive, cichorium endivia, chlorophyll, ascorbic acid, total sugars, inulin, NPK
Volume 5 Issue I - 2016

\author{
Helaly AA, Maray M, ASA Abo El Hamd,A \\ Mohamed
}

Department of Horticulture, Faculty of Agriculture, Al-Azhar

University, Egypt

\begin{abstract}
Correspondence: AA Helaly, Department of Horticulture,Faculty of Agriculture, Al-Azhar University, Cairo, Egypt, Email alaahelaly@hotmail.com
\end{abstract}

Received: September 17, 2016 | Published: October 28, 2016

\section{Introduction}

Endive (Cichorium endivia L var. crispum) belonging to the Asteraceae family, are popular vegetables consumed in various ways and increasing amounts, since they are perceived as being "healthy" and low caloric meal components. ${ }^{1}$ In addition to chicory's use a leafy salad vegetable, the roots of some cultivars are grown for use as a coffee substitute. Cichorium endivia is only known from cultivation. It was probably first brought into cultivation in the Mediterranean region, where it's wild relatives Cichorium pumilum Jacq. And Cichorium calvum Sch Bip. Both species can be considered as the progenitor of escarole and endive. Cichorium endivia was probably known to the old Egyptians, but no archaeological evidence has been found, while the ancient Egyptians regarded lettuce from the same family as an aphrodisiac $^{2} 1995$. It spread to central Europe in the 16th century and is now grown throughout Europe and North America. ${ }^{3}$ For vegetative growth plant length character has been most easily and frequently measured. Thus, on chard it was found that there was a gradual increase in plant height during growth stages up till the end of plants age. ${ }^{4}$ On cabbage and some vegetable plants it was showed little growth in their height up to planting in field and after that the plant height was increased regularly in beginning period of plant growth until to harvest which the growth was slowed down, ${ }^{5}$ El-Sherbeiny on sweet fennel and $\mathrm{Saleh}^{6}$ on red cabbage. From the important characters which clear the various growth stages of plant during developmental stages many characteristics such as leaves number per plant. From here, on chard, it was found that increasing in leaf number per plant took placed with the progress of plant development up to final plants age..$^{7}$ On lettuce, it was found that there was gradual increase in leaf number during plant development up to 12days from the stage of about 7 true leaves from sowing Burns et al. ${ }^{8}$ From the important characteristic to determine the growth of vegetable crops is measurement of the fresh weight per plant. However, in this part it was included some discussed of relation between growth and fresh weight on some vegetable plants. On cabbage, it was recorded that the head fresh weight increased quickly in the beginning period of development after that increased slowly with the processed of age. ${ }^{9-}$ ${ }^{11}$ The same studies showed that fresh weight of plants increased gradually during developmental stages till to last examined ages from planting Ayman et al., ${ }^{12}$ on parsley, Wayne and Richard on spinach, El-Sayed ${ }^{13}$ on chard. In red cabbage was found that the Plant fresh weight increased sharply up to the age of 90days after which a very slight increase occurred till the age of 110days followed by a slight reduction till 150 days age Kamal. ${ }^{14}$ On kohlrabi, it was found that plant fresh weight was increased progressively by advance in plant age up to 60days after transplanting.

So, it was found that in chard plants that chlorophyll content was increased during developmental stages up to 90days from sowing Salem, ${ }^{15}$ In lettuce, it was found that chlorophyll content was increased during the various growth stages El-Zawily et al., ${ }^{16}$ In another experiment on cabbage plants, it was noticed that the amount of chlorophyll pigments was higher in the oldest leaves and diminished with the decrease of leaf age. The content of ascorbic acid is one of the main important characteristic to the nutrition of human. It is found with a suitable quantity in vegetable crops. On lettuce, it was found that ascorbic acid content in lettuce plants decreased with age progress during the various developmental stages Borowski and Michalek, and El-Sayed, on chard. ${ }^{17}$ Dry Weight content in the portion used for food in vegetable plants is an important growth parameter for determining the proper age of harvest. Thus, in studies on some leafy vegetable crops were done on cabbage, parsley and chicory proved the previous trend indication that dry weight content was increased during the various growth stages (De Mole et al. ${ }^{18}$ On chard, it was found that the dry weight content in plants increased exponentially during growth until 90days from sowing. On lettuce, it was noticed in some examined varieties that the dry weight increased with the progress of age during growth of plant Riad et al. ${ }^{19}$ However, the same picture was noticed on sweet fennel as dry weight content showed quick increments during the various developmental stages until 
190days from sowing El-Sherbeiny. ${ }^{20}$ On kohlrabi, it was found that dry weight increased gradually during plant growth till 40days then exhibited slower increase till 60days from transplanting.

The quality of vegetable crops depends greatly upon their sugars content. On lettuce, was detected that total sugars increased during the various growth stages It was detected on chard plants Ford hook Jiant and Balady varieties that the total sugars content in both varieties increased quickly from the first examined age of 45 days after sowing till the age of 75 days after which this content decreased till the last age of 105 days .On red cabbage, it was noticed that the plant sugars content increased continuously till the age of 120days after which there were a slight decrease up to the last tested age of 150days.

Inulin in plant is considered one of the most important aspects in human nutrition. So, some trials were done to follow the changes in this content in some vegetable plants during development. On artichoke, it was found that insulin increased during the various growth stages Abd El-Salam. ${ }^{21}$ On Jerusalem artichoke, it was found that insulin content increased with age advance Meijer et al. ${ }^{22}$ Continuous studies on Jerusalem artichoke, it was found that insulin content increased till 120days from planting then a decrease trend took place after this stage of growth El-Sharkawy et al. ${ }^{23}$ Considerable attention has been paid by many workers to follow the major mineral contents, nitrogen, phosphorus and potassium during the growth of some leafy and some others vegetable. In sweet fennel, it was noticed that the content of nitrogen in the bulb increased rabidly with the progress of age till 150days from sowing where a quick drop was followed up to the final age of 190days El-Sherbeiny. ${ }^{24}$ In two varieties of chard, it was found that the contents of nitrogen increased quickly up to the age of 75 days from sowing, then decreased till the final examined age of 105 days. On red cabbage, it was noticed from results that the content of nitrogen showed that these elements increased with the progress of age till 120days then followed by a slight reduction till the age of 150days. In more research, the results indicated that the growth of sweet fennel, results shown that the contents of phosphorus in the bulb increased rapidly with age advance till 150days from sowing where a quick reduction was followed up to the final age of 190days. On two varieties of chard, it was noticed that the contents phosphorus increased quickly up to the age of 75 days from sowing, then decreased till the final examined age of 105days. In red cabbage, it was found that the content of phosphorus increased with the progress of age till 120days then followed by a slight reduction till the age of 150days. It was noticed that the potassium content attained the maximum values at 150days on sweet fennel 105days on chard 120days on red cabbage and 50days on kohlrabi. The objective of these experiments was carried out to study the Models of plant developmental stages to determinate the most suitable harvesting stages. Data were recorded on 6 labeled stages of plant growth which comprised $(45,60,75$, and 90, 105 and 120 days)

\section{Materials and methods}

The field experiments were carried out on the curled Endive (Cichorium endivia var. crispum L.) cv. Salad King (Figure 1) in private farm located at Giza governorate, Egypt during the two consecutive years of 2012/2013 and 2013/2014 A.D. The experiments were established to study the models of plant developmental stages during the plant growth and the most suitable harvesting stage.

The experiment took place to follow the developmental stages of the growing endive plants for determining the most suitable harvesting stage. Seeds were sown in seed trays on September $15^{\text {th }}$ and transplanted into the field on October 15th in both seasons. The treatment included four replicates and each replicate consisted of 5 rows, every row was $3.5 \mathrm{~m}$ long and $70 \mathrm{~cm}$ width. The distance between plants was $15 \mathrm{~cm}$. The plot area was $12.25 \mathrm{~m}^{2}$. Data were recorded on 6 labeled stages of plant growth which comprised (45, 60, 75, 90, 105 and 120days) from transplanting date. Ten plants from every age were chosen for the physical and chemical analyses. Data were recorded:

i. Plant physical characteristics (Plant length, leaves number per plant and fresh weight per plant).

ii. Plant chemical characteristics (total chlorophyll, Ascorbic acid, dry weight, total sugars, insulin, nitrogen, phosphorus and potassium content).

\section{A. Physical characteristics determination procedures:}

i. Plant length was estimated in $(\mathrm{cm})$ as follow: endive rosette was held straight upward and measured from the stem cotyledonary nod up to the highest point of the rosette by measuring tape.

ii. Leaves number per plant was counted.

iii. Fresh weight per plant was determined by balance.

B. Chemical characteristics determination procedures:

0. Ascorbic acid (mg/100g. f. w.) in plant leaves was estimated by titration with 2, 6-dichlorophenolindophenol dye according to A.O.A.C.,

I. Dry weight was determined as (g/100g few.) by subjecting $100 \mathrm{~g}$ fresh weight then oven dried at $70^{\circ} \mathrm{c}$ till constant weight was reached.

II. Total sugars were determined as (\%) dry weight according to Smith et al. ${ }^{25}$

III. Inulin was determined according to A.O.A.C.

IV. Total chlorophyll content (mg/100 g. f. w.) in plant leaves was determined by the spectrophotometric method described by Hipkins et al. ${ }^{26}$

V. Total nitrogen was determined as (\% d.w.) according to the microkjeldahl method described in A.O.A.C. (2000).

VI. Total phosphorus was determined by Flame photometer according to Cottenie et al. ${ }^{27}$

VII. Total potassium was determined by Flame photometer according to Cottenie et al. ${ }^{27}$

Yield:

a) Fresh weight per rosette (g/rosette): average fresh weight of endive leaf rosette was estimated in ( $\mathrm{g} /$ rosette) by balance.

a. Yield per plot $(\mathrm{kg})$ : total yield of endive leaf rosettes were estimated in $(\mathrm{kg})$ by a balance.

\section{Statistical analysis}

The obtained data of the first experiment were statistically analyzed by using goodness of fit method (George,. ${ }^{28}$ Significant differences among the experimental plants were observed. Harvesting dates were compared using the least significant difference (LSD) at $5 \%$ probability, according to Snedecor et al. ${ }^{29}$ (Figure 1). 


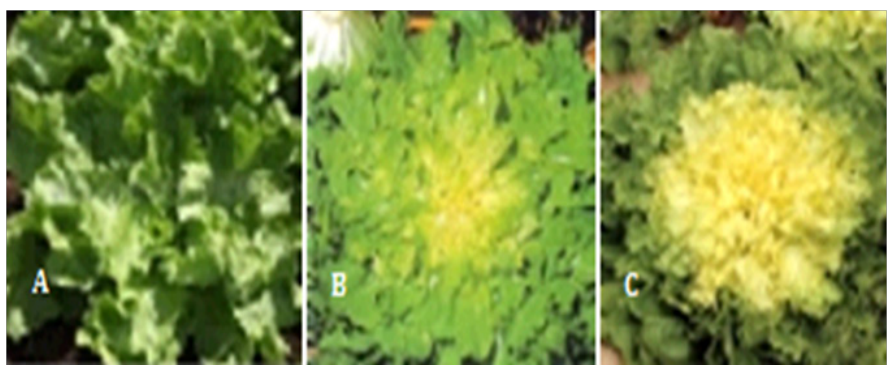

Figure I Endive plants developmental stages at the age of 60 days (a), 90 days (b) and I 20 days (c).

\section{Results and discussions}

The growth and developmental stages of endive plants cv Salad king had been followed by measuring a number of physical attributes (such as plant height, fresh weight, leaves number) and chemical contents (such as ascorbic acid, total chlorophyll, total sugars, dry weight, insulin, nitrogen, phosphorus and potassium). Growth curves based on these measurements showed characteristic forms which have been the subject of our discussion.

\section{Plant physical characteristics}

The data of plant physical characteristics (plant length, leaves number per plant and fresh weight per plant) during the growing period in the two seasons of 2012/2013 and 2013/2014 is shown in The Figure 2 results exhibit a rapid increment in the first periods of growth until the age of 90days then followed by a slow increase up to 120days. From the statistical point of view, it is clear that the development of the plant length formed a curvilinear type with the advance of age in both seasons. However, the plant length increased sharply till the age of 90days, and then the increase rates turned to be slower till the age of 120days. Leaves number per plant was changed during the different developmental stages of endive during both seasons. It is apparent that the gained values followed a curvilinear with the forge ahead of plant age. However, the resulted figures show that leaves number increased clearly till the age of 90days then the increments were relatively very low up to the age of 120days in two seasons. Fresh weight per plant was changed during the different developmental stages of endive in both seasons. The results show a fast increment in the first periods of growth until the age of 90days then followed by a slow increase up to 120days in the two seasons. From the statistical point of view, it is obvious that the development of the curd weight formed a curvilinear type with the advance of age in the both of experimental seasons. From the statistical point of view, the results suggested a curvilinear relationship. However, the plant fresh weight increased sharply till the age of 90days, and then the increases rate turned to be slower till the age of 120days. The obtained results of curd development cleared that plant length, leaves number per plant and fresh weight were characterized with a rabid growth period from the age of 15 to 90 days then a slow trend was occurred at the age of 90days till the age of 120days. The increase in the physical characteristics may be attributed to the natural considerable cell expansion after the early period of cell division Reeve, et al., ${ }^{30}$ on potato and Abo El- Hamd, on tomato $)^{30}$ In more details, cell division in the first phase of growth consists entirely from the division of meristematic cells. Certain daughter cells are pushed away from the zone of division and produced to the next phase of growth which is cell enlargement. These cells are supplied with large quantities of water and food which may become several times of their former size. Physiologically speaking, the work done on some fruits Abo El- Hand on tomato. ${ }^{31}$

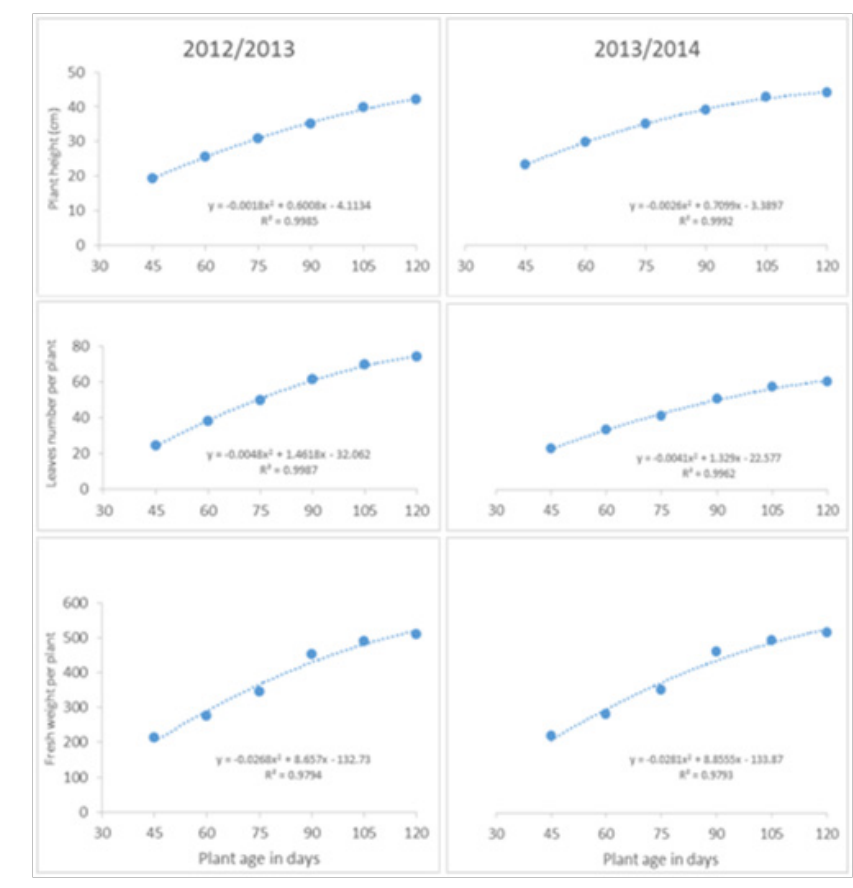

Figure 2 Changes in physical characteristics during various developmental stages in 2012/2013 and 2013/2014 seasons.

On the other hand, the previous pattern of growth may be also due to the quantity of solar radiation which intercepted by the plant canopy. Thus, after the plant emerge the leaf area is small then by continuous growth more radiation each day was gained and the potential growth rate increases initially in an exponential manner. However, as the plant canopy continues to expand, the mutual shading of both leaves within and between plants increases. Eventually, the amount of light intercepted per unit of foliage declines with a concomitant decline in the relative growth rate Marshall and Porter. ${ }^{32}$ Related the periods of increase to the changes happened in the levels of IAA, GA3, and cytokinins. It is worthy to mention that the plants grow by the process of cell division or mitosis followed by cell enlargement and maturation. Basically, cells will be differentiating into tissues that make up the organs of the plants. This growth processes may be measured as a change in mass, volume or length of shoot or root. Nevertheless, the crop productivity is often expressed not in biomass but in yield of the desired product such as leaf, flower, fruit, seed, root, oil, protein or other specific chemicals Smith et al. ${ }^{33}$ These growth substances may increase progressively in the periods of growth then tended to lessen in the latter stages of development. Regarding the results of chlorophyll, it was found that the concentration of chlorophyll pigments increased continuously till the age of 90days after which a slight decrease occurred up to the last examined age of 120days. However, the changes happened in chlorophyll concentration may be due to the chlorophylls activity in the breakdown of chlorophyll by catalysis the removal of the phytol group Hulme. ${ }^{34}$ (Figure 2) Changes in physical characteristics during various developmental stages in 2012/2013 and 2013/2014 seasons. 


\section{Plant chemical characteristics}

The observation of chemical changes in endive plants during their developmental stages such as ascorbic acid, dry weight, total sugar, insulin and total chlorophyll in the two seasons 2012/2013 and 2013/2014 are presented in Figure 3 The changes in ascorbic acid content during the endive plants development in both seasons show pointed obviously that ascorbic acid content increased quickly with age progress till the age of 90 days which was followed by a slight drop in the following last age of 120days. The figures showed that the statistical relationship between the levels of this vitamin and the different developed ages is of curvilinear type. Dry weight per plants was changes during its developmental stages in the experimental seasons. From the statistic point of view, it is clear that there was an increase trend in the dry weight content with progress of age developed in a curvilinear form. The increasing in dry weight content began from the first studied age of 45 days slowly gradually till the age of 90days then it trended to gain slight increments till the final examined age of 120days in the two seasons. Referring to total sugars contents it was changes in endive plants during the various developmental stages in the two experimental seasons. It is clear this, the total sugars increased quickly with the progress of age till 90 days which followed by a drop in the last age of growth at 120 days. The trend of total sugars during the developmental stages reflected curvilinear type from the statistical point of view. The changes of insulin content were observed during the different of developmental stages in both seasons and the figure suggested a curvilinear type. The results reflected a continuous increasing in insulin contents till the age of 90days, the increases were relatively slow then it turned to be sharp till the age of 90days after which a slight decrease took place till the last examined age of 120days in both seasons. The changes in chlorophylls content were appeared during plant growth and developmental stages in both growing seasons. It is clear from the figure that the relationship between various examined ages and the concentrations of chlorophylls content suggested being a curvilinear type. However, it is clear that the content of chlorophyll continued to increase till the age of 90days after which there were a slight decrease up to the last tested age of 120days.

If we have a look to the obtained data of the chemical contents, the results revealed continuous increase in the trend of ascorbic acid, total sugars and insulin showed that these contents increased sharply till the age of 90days which was followed by a decrease till the last examined age of 120 days. This picture may be ascribed to the concentration and activity of ascorbic acid dehydrogenate which catalyze the reduced dehydroascorbic acid (oxidized state) to L- ascorbic acid (reduced state) where the level and activity of ascorbic acid dehydrogenase are high at the earlier growth stages than the later ones Yamaguchi et al. ${ }^{35}$ To explain the trend of ascorbic acid, it is easy to say that the natural occurring ascorbic acid is L- ascorbic acid and the other ascorbic analogues. Fruits synthesize this vitamin from the precursor of hexose sugars which depends on an adequate photosynthetic activity Thus, the increase in this vitamin during curd development may be due to the high rate of hexose sugars synthesis and in the contrary the decrease may be attributed to its exhaustion during respiration and its transfer to the oxidized form In addition, the increase in the level of ascorbic acid may also related to the increase in the amount of sugars particularly D- glucose which converted into this vitamin Davies et al. ${ }^{36}$ From another point of view, the continuous increase in curd dry weight during growth may be attributed chiefly to the increase in sugars content during growth as the curd dry weight in cauliflower composed mainly from sugars beside, the progressive accumulation of nutrients which sink in the curd from another plant parts and at the same time the reduction in curd moisture.

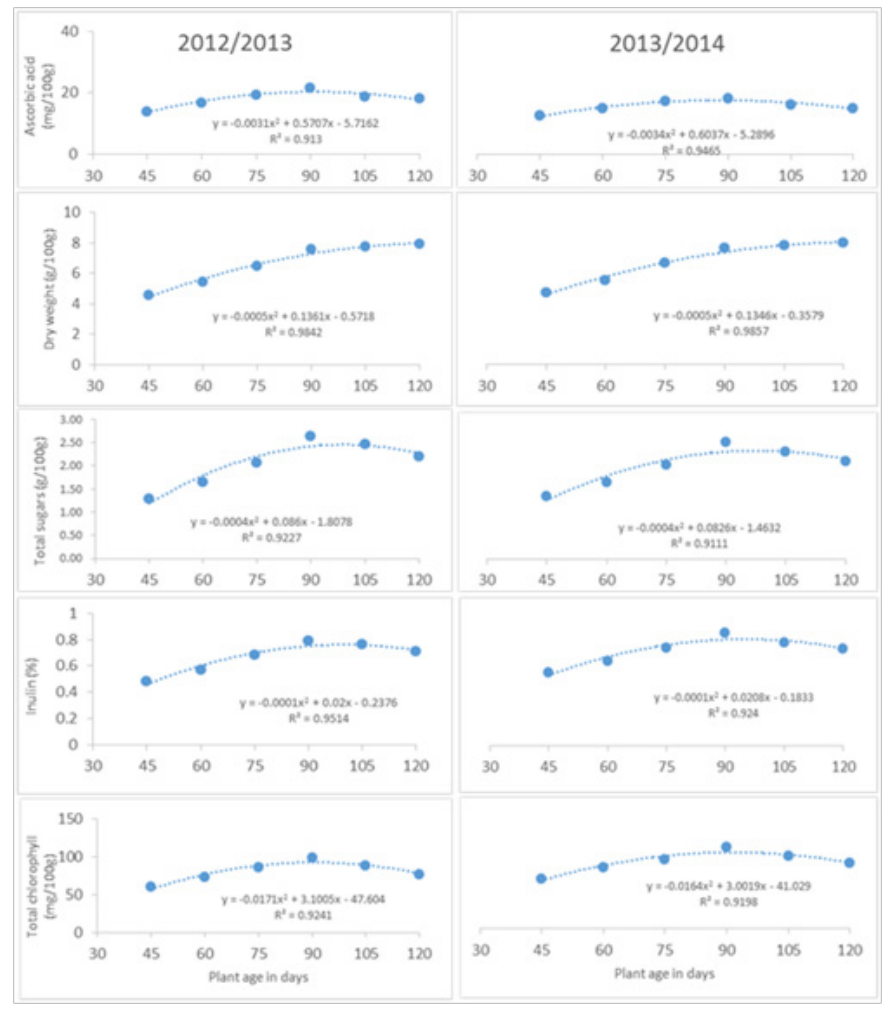

Figure 3 Changes in chemical characteristics during various developmental stages in 20I2/20I3 and 20I3/2014 seasons.

Concerning total sugars and insulin, it is reported that the main sugar transport from the leaves to the fruits during growth is sucrose. While part of this sugar is used for the synthesis of pectic substances and other cell- wall materials other part converted to usual storage product starch. However, it was reported that before flowering of Jerusalem artichoke plants about $70-80 \%$ of photosynthesis production of carbohydrates were retained in stalks and in turn increased in leaves. Then, after flowering, the reserves which were accumulated in stalks were transferred to the tubers Caserta et al. ${ }^{37}$ This translocation from the stalks and old leaves towards the tubers induced the shown decrease in carbohydrates and insulin contents after the age of 120days Degidio et al. ${ }^{38}$ Nevertheless, the possible reason for the slight decrease happened after the age of 90days till the age of 120days is the relative increase in temperature at this period of growing season where it is known that sugars content in cabbage were reduced much at $25^{\circ} \mathrm{C}$ than 20 or $15^{\circ} \mathrm{C}$ as a result of increasing carbon loss by respiration Hara and Sonoda. ${ }^{39}$ So, it is easy here to suggest that in the early growth of curd stages which was characterized with high sugars, the accumulation of these sugars may be higher than the rate of conversion to starch and cell- wall materials whereas in the late stages which showed lower sugars concentration the opposite may be true. Figure 3 Changes in chemical characteristics during various developmental stages in 2012/2013 and 2013/2014 seasons.

The changes in nitrogen, phosphorus and potassium in endive plants during different developmental stages in the two experimental seasons of 2012/2013 and 2013/2014 are presented in Figure 4. The obtained results exhibited that the nitrogen changes in endive plant leaves showed curve suggested a parabola type relationship between 
this content and age progress in both experimental seasons. However, the values showed that there was a continuous increasing in total nitrogen in leaves up to the age of 90days then a decreasing occurred till the final checked age of 120 days. The changes in plants phosphorus content during the various developmental stages exhibited a parabola type relationship between phosphorus content and the developed ages in the two seasons. However, the levels of phosphorus content increased with age progress from the first examined age of 15 days up till the age of 90days in two seasons, followed by a quick drop occurred in phosphorus content till the last age of 120days. Related to the potassium content in endive leaves during the developmental changes, it was found that the relationship between plant potassium content and the progressed ages suggested being of a parabola shape. However, this content increased quickly up to the age of 90days then it decreased slowly in the last following ages till the age of 120days. The obtained results of $\mathrm{N}, \mathrm{P}$ and $\mathrm{K}$ showed that these elements increased with the progress of age till 90 days then followed by a slight reduction till the age of 150days. However, the reason for the continuous increase of N, P and K contents till the age of 120days may be referred to the increase in the activity of absorption and translocation of these elements to the head with age progress On the other hand, the decline noticed in the last three ages might be due to the reduction in the metabolic efficiency of the plant which causes a reduction in uptake of these elements (Figure 4) Changes in nitrogen, phosphorus and potassium contents during various developmental stages in 2012/2013 and 2013/2014 seasons.

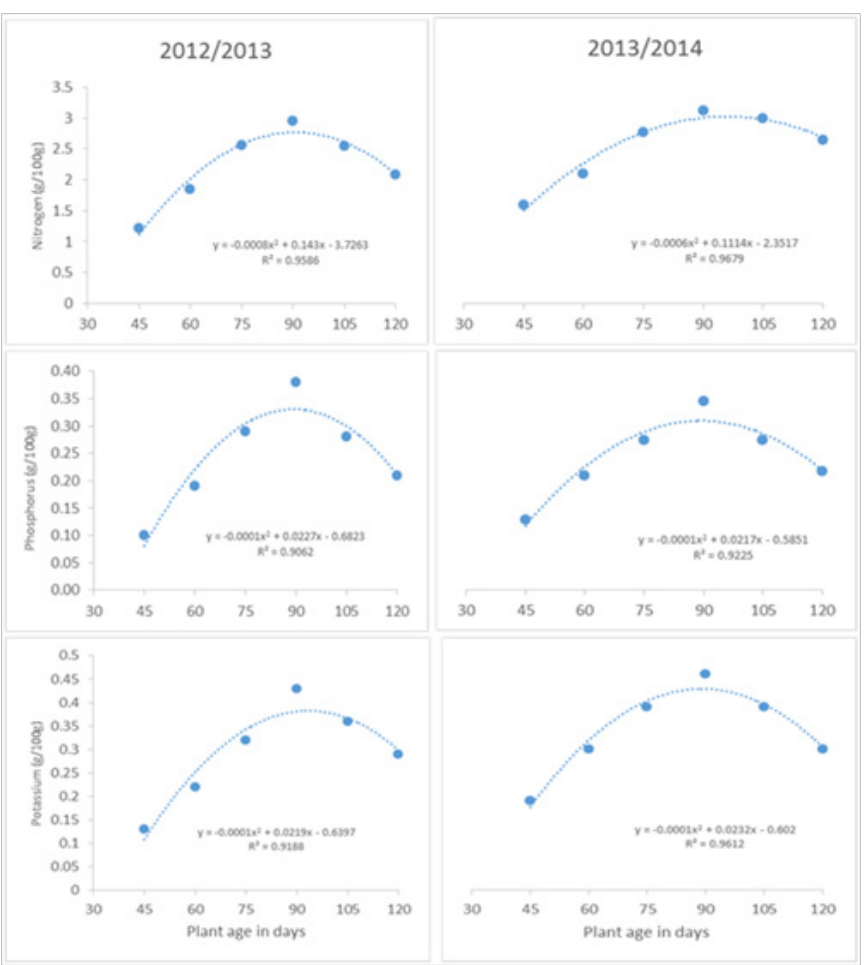

Figure 4 Changes in nitrogen, phosphorus and potassium contents during various developmental stages in 20I2/20I3 and 20I3/20I4 seasons.

\section{Recommendations}

The results of our experiments recommended that the best harvest should be advice for the best physical, and chemicals characteristics was obtained at the age of developmental stage 90days after planting.

\section{Acknowledgements}

The authors express their gratitude to Prof. Dr. Abd El-Naem Said Abd El-Rehim and Prof. Dr. Adel Abd El-Aziz Mohamed at Department of Horticulture, Faculty of Agriculture, and Al-Azhar University for their constructive suggestions, supervision, advice, sincere help and valuable guidance throughout the course of this study.

\section{Conflict of interest}

The author declares no conflict of interest.

\section{References}

1. DuPont MS, Mondin Z, Williamson G, et al. Effect of variety, processing, and storage on the flavonoid glycoside content and composition of lettuce and endive. J Agric Food Chem. 2000;48(9):3957-3964.

2. Morton RS. Sexual attitudes preferences and infection in ancient Egypt. Genitourin Med. 1995;71(3):180-186.

3. Grubben GJH, Denton OA. Plant resources of troplical Africa 2 vegetables. PROTA foundation, Wageningen, Netherlands/ Backhuys publishers, leiden, Netherlands/CTA, Wageningen, Netherlands; 2004. $668 \mathrm{p}$.

4. Raul EF, Aljaro AU, Ruz RS, et al. Behavior of 42 crop specees grown in saline soils with high boron concentration. Agricultural Water Management. 1997;34(2):111-124.

5. Unissen J, Sins A. Growth stages of Brassica for crop protection purposes. Scientia Horticulturae. 1984;24(1):1-11.

6. Saleh, SAHAA. Physiological studies on growth and production of kohlrabi (Brassica oleracea var gongylodes L.). Egypt: Faculty of Agriculture Al-Azhar University; 2011

7. El-Sayed AEA. Studies on growth and salinity tolerance of chard plants. M.Sc. Thesis. Fac. Agric. Al-Azhar Univ; 2003.

8. Burns IG, Miles PD, Scaife A. Long term effects on growth and development of short periods of $N$ deficiency during the seeding stage of lettuce. Proc Second congress of the European Soc. Agro. Warwich Univ; 1992. p. $40-41$

9. Lill RE, Read AI. Cabbae: Effect of head maturity on cole slaw color. New Zealand Commercial grower. 1983;37:18.

10. Nilsson T. Growth and carbohydrate composition of winter white cabbage intended for long- term storage. I. Effects of late $\mathrm{N}-$ fertilization and time of harvest. Journal of Horticulture Science. 1988;63:419-429

11. Nilsson T. Growth and carbohydrate composition of winter white cabbage intended for long- term storage. II. Effects of solar radiation, temperature and degree - days. Journal of Horticulture Science. 1988;63:431-441.

12. Ayman FAH, MS Hussein, HA El-Saeid. Heavy metal composition of leafy vegetables as influenced by different nitrogen sources. J Hort. $193 ; 20(2): 205-215$.

13. Wayne M, Richard CL. Acclimation of photosynthesis, to low temperature in Spinacia oleraca L. 1. Effects of acclimation on Co2 assimilation and carbon partitioning. Journal of experimental Botany. 1997;48(315):18651872 . 
14. Kamal ZAZ. Physiological studies on growth and production of red cabbage. Egypt: Fac Agric Al-Azhar University; 2004.

15. Salem HHH. Physiological studies on salt tolerance of some vegetable crops. Egypt: Fac Agric Ain Shams University; 1974.

16. El-zawily AI, Mashaal SF. Effect of foliar nutrition with minor elements on lettuce (Lactuca sativa L.) 1-Effect on growth, yield and leaf mineral status. Egypt: Faculty of Agriculture Tanta University; 1984.

17. Borowski E, michalek S. Effect of state produced hydrogel addition to peat substrate on yield and quality of lettuce fed with N-NO3 or N-NH4. Part II. Content in the leaves of certain organic and mineral substances. Sectio EEE Horticutura. 1998;6:117-128.

18. De Mole CP, Everaarts AP. Growthdevelopment and yield of white cabbage in relation to time of planting. Acta Hortticulture. 1990;267:279288.

19. Riad WY, AA El-shamey, WM Rizk. Trials on production and storage ability of some lettuce cultivars 11th International congress for statistics, computer Sci., Soc. and demographic research, Cairo- Egypt; 1986. p. 109-126.

20. El-Sherbeiny MA. Studies on the development and production of sweet fennel. Egypt: Faculty of Agriculture Tanta University; 1999.

21. Abd El-Salam AS. Physiological studies on maturity, ripening, handling and storage of artichoke. Faculty of Agriculture Ain Shams University; 1966.

22. Meijer WJ, Mathijssen EWJM. The relation between flower initiation and sink strength of stems and tuber of Jerusalem artichoke. Journal of Agriculture Science. 1991;39(2):123-135.

23. El-Sharkawy ZA. Physiological studies on Jerusalem artichoke. Egypt: Faculty of agriculture Cairo University; 1998.

24. El-Sherbeiny MA. Studies on the development and production of sweet fennel. Fac Agric Al- Azhar Univ; 1999.

25. Smith FMA, Hamilton GDK, Michel, et al. Colorimetric method for determination of sugars and related substance. Anal Chem. 1956;28(3):350-356.

26. Hipkins MF, NR Baker. Photosynthesis energy transduction. In Hipkins MF, et al. editors. Spectroscopy. IRL. UK: Oxford; 1986. p. 51-105.
27. Cottenie A, Verloo M, Kiekens L, et al. Chemical analysis of plant and soils. Laboratory of Analytical and Agrochemistry, Belgium: State University of Gent; 1982.63 p.

28. George BA. Correlation and regression. A supplement to "Experimental methods for extension works" university of California, Agricultural extension service. USA; 1963.

29. Snedecor GW, WG Cochran. Statistical methods. 7th ed. Iowa, USA: Iowa State University Press Ames; 1980.

30. Reeve RM, Timn H, Weaver LM. Parenchyma cell growth in potato tubers. American Potato Journal. 1973;50(2):49-57.

31. Abo El-Hamd ASA. Physiological studies on the developmental stages, handling and storage of tomato. Faculty of agriculture. Egypt: AL-Azhar University; 1981.

32. Marshall BJR Porter. Concepts of nutritional and environmental interaction determining plant productivity, In: JR Porter, et al. editors. Plant growth: Interaction with nutrition and environment. USA: Univ Press; 1981.

33. Smith BN, Harris LC, McCarlie VW, et al. Time, plant growth, respiration and temperature, In: M Pessarakli editor. Handbook of plant and crop physiology. INC, New York: Marcel Dekker; 2002. p. 1-11.

34. Hulme AC. The biochemistry of fruits and their products. 1st Ed, London and New York: Academic Prsess; 1970.

35. Yamaguchi M, Joslyn MA. Investigations of ascorbic acid dehydrogenase of pease (Pisum sativum) and its distribution in the developing plant. Plant Physiol. 1951;26(4):752-771.

36. Davies MB, Austin JA, Partridge DA. Vitamin C: Its chemistry and Biochemistry Published by the Royal Society of chemistry, Thomas's Graham House. Science Park, Cambridge; 1991.

37. Caserta G, Cervigni T. The use Jerusalem artichoke stalks for the production of fructose or ethanol. Bioresoure Technology. 1991;35(3):247-250.

38. Degidio MG, Cecchini C, Cervigni T, et al. Production of fructose from cereal stems and polyannual cultures of Jerusalem artichoke. Industrial Crops and Products. 1996;7(2-3):113-119.

39. Hara T, Sonoda Y. Cabbage - head development as affected by nitrogen and temperature. Soil Sci and Plant Nutrition. 1982;28(1):109-117. 